Neuroepidemiology 2011;37:259

DOI: $10.1159 / 000334512$

\section{Is Intensive Cholesterol Lowering Detrimental in Multiple Sclerosis?}

Luca Mascitelli ${ }^{a}$, Mark R. Goldstein ${ }^{\text {b }}$

aComando Brigata Alpina 'Julia', Medical Service, Udine, Italy;

${ }^{b} \mathrm{NCH}$ Healthcare Group, Naples, Fla., USA

Statin drugs, beyond their cholesterol-lowering effect, have anti-inflammatory and immunomodulatory properties, and have been shown to suppress acute experimental autoimmune encephalomyelitis in rats [1]. It has therefore been hypothesized that addition of a statin to interferon-beta-1a therapy for relapsingremitting multiple sclerosis (MS) might improve annualized relapse. Indeed, two small trials $[2,3]$ showed that low doses of statins (simvastatin $40 \mathrm{mg} /$ day and atorvastatin $20 \mathrm{mg} /$ day, respectively) in addition to interferon beta- 1 therapy were of some benefit. In fact, the real benefit of statins in these studies $[2,3]$ is difficult to find out with certainty, given the meager study sizes (of 85 and 45 patients, respectively). However, it has recently been found in a larger study of 307 patients [4] that high-dose simvastatin ( $80 \mathrm{mg} / \mathrm{day})$ as add-on therapy to intramuscular interferonbeta-1a for treatment of relapsing-remitting MS was not beneficial. Furthermore, the nonsignificant suggestion of better results in the control group confirmed the results of a previous randomized trial in which the combination of high dose atorvastatin $(40$ or $80 \mathrm{mg} /$ day) with interferon-beta-1a increased MS disease activity [5].

We suggest that at high statin doses, the drug-induced cholesterol depletion itself is detrimental, overwhelming any potential immunomodulatory and anti-inflammatory action.

It is well known that disseminated demyelinated lesions within the central nervous system are the hallmark of MS. However, a considerable portion of MS lesions shows signs of new myelin formation (remyelination) that may depend on recruitment of oligodendrocyte precursor and growth factor signaling on mature oligodendrocyte which are the primary producers of cholesterol in the brain. Endogenous cholesterol biosynthesis, the target of statin therapy, is essential for myelin membrane growth and is a key component of cellular membranes and particularly of lipid rafts, which are cholesterol- and sphingolipid-enriched membrane microdomains that function as platforms that concentrate and segregate proteins within the plane of the bilayer [6]. Lipid rafts are thought to be required for oligodendrocyte differentiation and are involved in the general signaling mechanisms that initiate myelination by means of regulation of the cytoskeleton and directing myelin components.

The heterogeneity of MS, a hallmark clinical characteristic, is not well understood. However, it is plausible that intrinsic regenerative capacities contribute to functional recovery during the re- mitting phase of MS. Indeed, in most MS cases, numerous demyelinating and remyelinating events occur during the decades-long disease course. Therefore, in addition to the resolution of inflammation, remyelination seems to contribute to functional recovery in MS patients. Because oligodendrocytes are highly metabolically active during myelin formation, any negative interference, such as inhibition of cholesterol biosynthesis by statins, may result in failure of remyelination [7].

On the other hand, a wealth of evidence has established that statin-mediated cholesterol synthesis inhibition negatively affects intrinsic properties of oligodendrocytes during remyelination [810], a process that may become particularly important during the recovery phase in MS when inflammation declines.

Therefore, long-standing cholesterol depletion by statin treatment may negatively influence the intrinsic remyelinating capacity in MS patients, and may actually increase clinical disease activity. We feel that statins, particularly at high doses, should be avoided in patients with MS.

\section{Disclosure Statement}

None.

\section{References}

-1 Stanislaus R, Singh AK, Singh I: Lovastatin treatment decreases mononuclear cell infiltration into the CNS of Lewis rats with experimental allergic encephalomyelitis. J Neurosci Res 2001;66:155-162.

$\checkmark 2$ Togha M, Karvigh SA Nabav M, et al: Simvastatin treatment in patients with relapsing-remitting multiple sclerosis receiving interferon-beta 1a: a double-blind randomized controlled trial. Multiple Sclerosis 2010; $16: 848-854$.

-3 Lanzillo R, Orefice G, Quarantelli M, et al: Atorvastatin combined to interferon to verify the efficacy (ACTIVE) in relapsing-remitting active multiple sclerosis patients: a longitudinal controlled trial of combination therapy. Multiple Sclerosis 2010;16:450-454.

-4 Sorensen PS, Lycke J, Eralinna JP, et al; for the SIMCOMBIN study investigators: Simvastatin as add-on threrapy to interferon beta-la for relapsing-remitting multiple sclerosis: a placebo-controlled randomised phase 4 study. Lancet Neurol 2011;10:691-701.

5 Birnbaum G, Cree B, Altafullah I, Zinser M, Reder AT: Combining beta interferon and atorvastatin may increase disease activity in multiple sclerosis. Neurology 2008;71:1390-1395.

6 Wainwright G, Mascitelli L, Goldstein MR: Cholesterol lowering therapies and membrane cholesterol. Stable plaque at the expense of unstable membranes? Arch Med Sci 2009;5:289-295.

7 Saher G, Brügger B, Lappe-Siefke C, et al: High cholesterol level is essential for myelin membrane growth. Nat Neurosci 2005;8:468-475.

8 Klopfleisch S, Merkler D, Schmitz M, et al: Negative impact of statins on oligodendrocytes and myelin formation in vitro and in vivo. J Neurosci 2008;28:13609-13614.

-9 Miron VE, Zehntner SP, Kuhlmann T, et al: Statin therapy inhibits remyelination in the central nervous system. Am J Pathol 2009;174:18801890.

10 Smolders I, Smets I, Maier O, vandeVen M, Steels P, Ameloot M: Simvastatin interferes with process outgrowth and branching of oligodendrocytes. J Neurosci Res 2010;88:3361-3375.

\section{KARGER}

Fax +41613061234 E-Mail karger@karger.ch www.karger.com
(C) 2011 S. Karger AG, Basel 0251-5350/11/0374-0259\$38.00/0

Accessible online at: www.karger.com/ned
Luca Mascitelli, MD

Comando Brigata Alpina 'Julia', Medical Service

8 Via S. Agostino

IT-33100 Udine (Italy)

Tel. +39 043258 4044, E-Mail lumasci@libero.it 